\title{
Predicting the accuracy of public perceptions of charity performance
}

Received: 13th November, 2002

\section{Roger Bennett}

is a professor of marketing in the Centre for Research in Corporate and Marketing Communications at London Metropolitan University. Roger's main research interests lie in the field of nonprofit and voluntary sector marketing, especially the effectiveness of various forms of advertising imagery used by charitable organisations.

\section{Sharmila Savani}

is a lecturer in business studies at Harrow College. Previously she was employed as a research assistant in the Centre for Corporate and Marketing Communications at London Metropolitan University, where she worked on a number of research projects in the areas of nonprofit and local government marketing.

Abstract An extensive literature has examined the proposition that public perceptions of a charity's level of efficiency (evidenced, for instance, by the ratio of its administration and fundraising costs to total expenditures) impact heavily on its capacity to attract donations. Yet little is known about the factors that determine the accuracy of donor evaluations of charity performance or about the linkages between inaccurate ratings and the favourability of a person's attitudes towards charities. This empirical study employed two of Cronbach's ${ }^{1}$ measures of the accuracy of attribute ratings (differential accuracy and differential elevation) as a means for exploring possible relationships between the precision with which an individual evaluates various charity performance indices and his or her willingness to give. Two potential antecedents of ratings accuracy were assessed: the provision of relevant information on a charity's efficiency in areas collateral to the performances to be inferred and a person's knowledge of and familiarity with the charity sector. Additionally, the investigation queried the degrees to which the sample respondents believed that certain performance attributes covaried with others.

Roger Bennett Department of Business and Service Sector Management, London Metropolitan University, 84 Moorgate, London EC2M 6SQ, UK.

Tel: +44 (0)20 7320 1465; Fax: +44 (0)20 7320 1465; e-mail:

r.bennett@londonmet.ac.uk

\section{INTRODUCTION}

Numerous empirical studies of donor behaviour have concluded that public perceptions of a charity being 'inefficient' and/or spending too much of its income on marketing and advertising exert significantly negative influences on its ability to raise funds. ${ }^{2-10}$ Attitudes about a charity's performance in these respects help position the organisation in the public mind, create expectations about its activities and generate comparisons with other charities that might affect donations. ${ }^{11}$ Similar considerations apply to perceptions that a charity has been 'mismanaged' in some way by its administrators or trustees. ${ }^{12-18}$ It follows, therefore, that the accuracy of donors' perceptions of a charity's attributes vis-à-vis administrative and marketing efficiency can substantially influence their evaluations of the organisation as a whole and hence their willingness to give to the charity. 
The accuracy with which members of the public assess such matters has implications extending well beyond marketing and fundraising. It is highly relevant, for instance, to the question of how charities should respond to calls for greater accountability, performance measurement and value for money auditing in the nonprofit sector. ${ }^{19-20}$ National newspapers take a keen interest in charity efficiency, ${ }^{23}$ indeed the possibility of the publication by one or more newspapers of "charity league tables' based on various performance indices is increasingly rumoured. The issue is also pertinent to the matter of how favourably actual and potential donors regard mergers within the charity sector. Do members of the public believe that large (merged) charitable organisations will be more efficient than small ones? Hyndman and McKillop ${ }^{24}$ reported the existence of significant economies of scale in relation to administration costs to income ratios among the UK's top 500 fundraising charities, although marketing expenditures were relatively higher in large organisations. The authors interpreted the latter finding in a positive manner, on the grounds that it suggested that cost savings were being diverted to finance marketing programmes that would generate additional income.

Despite the obvious importance of accurate public perceptions of charity 'efficiency' for charity marketing and management, the subject has not been extensively researched and, according to Sargeant et al. 'it remains unclear how donors actually draw their conclusions' about operational expenditures. ${ }^{25}$ Accordingly, the research reported in the present paper attempted

(i) to measure the accuracy with which a sample of members of the public assessed the performances of a number of UK charities in apposite respects;

(ii) to examine the effects of two critical variables (the provision of information and a person's pre-existing knowledge of the charity sector) on whether respondents believed that certain performance attributes covaried with others.

\section{LITERATURE REVIEW}

Misconceptions concerning how much of their incomes charities spend on administration and marketing are seemingly commonplace. For instance, a survey of 906 people completed by the UK Charities Aid Foundation (CAF) in 1986 found that 64 per cent of the respondents agreed that 'most charities waste too much in administration costs'; while 17 per cent agreed that charities 'are run by disorganised amateurs'. ${ }^{26}$ On average the respondents believed that only 50 pence in the pound of any charity's income actually reached the good cause for which a donation was intended. Conversely, they asserted on average that 78 pence in the pound ought to be spent on the charitable cause and not on administration. This matched the outcome to Warwick's ${ }^{27}$ study of US donors which found that most people thought that the ratio of administration/fundraising costs to charitable expenditure should be about 20:80. As in the CAF survey, however, the majority of donors were under the impression that the actual ratio was around 50:50.

Sargeant et al. ${ }^{28}$ similarly noted a general feeling among the public that charities were well meaning but inefficient. Their survey of 980 active givers to charity and 249 non-givers revealed that, on average, the latter group believed that only 45.5 per cent of the money donated to a charity would 
be spent on the charity's programmes. Even active givers assumed that only 67 per cent of revenues went to the good cause. Sargeant et al. noted that the true figure was well over 80 per cent. (Paton $^{29}$ reported that the average administration cost to expenditure (as opposed to income) ratio of the UK's top 500 charities in 2001 was just 7.3 per cent.) Clearly, Sargeant et al. continued, gaps in perception of these magnitudes could be extremely damaging to a charity's ability to attract donations. Evidence supporting this assertion emerged from a study undertaken by Harvey and McCrohan ${ }^{30}$ which found that charities which spent more than 60 per cent of their donor incomes on concrete charitable programmes (as opposed to campaigning, which involves heavy expenditures on marketing and advertising), and which vigorously publicised this fact, achieved significantly higher levels of donations. Likewise, a 1994 MORI poll revealed that 87 per cent of a sample of 2,000 committed donors regarded the quality that 'the charity makes good use of the money it receives' as a key determinant of their decisions to give. ${ }^{31}$ Indeed, a concern with value for money was cited more frequently as a factor in choosing charities than were specific charitable objectives. Efficiency and effectiveness were mentioned by about 75 per cent of the respondents; the importance of the charity as 'a caring concern' came third, with 72 per cent specifying this characteristic.

It is known that UK charities increasingly employ highly qualified and well-paid marketing and other professionals (especially database management staff). ${ }^{32}$ Fenton et al.'s analysis of the comments of 138 participants in focus groups found that the theme of managerial efficiency frequently recurred. Participants were 'anxious that their donations were not swallowed up in malpractice or needless bureaucracy'. ${ }^{33}$ Hence charities were expected to be managed efficiently and in a businesslike manner; not by 'disorganised amateurs who might waste money on administration through lack of expertise'. Unfortunately, however, the respondents' views were often inconsistent, with the employment of highly paid professionals regularly being regarded as 'incongruous' with charitable behaviour. Donors frequently asserted that they did not want to 'finance the wages of professionals' but wished rather to 'alleviate the suffering of the needy'. Thus, charities were required to be highly efficient, yet run 'as a labour of love' by non-specialist managers.

Accordingly, charities that spent relatively small proportions of the income they received from donors on employee salaries and benefits were seen as 'better' and more efficient. Yet, at the same time, the incompetence associated with amateurism was abhorred, even though professionally qualified employees were perceived as costly and uncaring.

\section{KEY INDICATORS}

Several accounting ratios are routinely employed to measure charity efficiency, including fundraising expenditure to income; administration expenditure to income; expenditures on charitable programmes to total expenditure; and 'value for money' (typically expressed in terms of income per paid employee, relative salary costs, income generated by each $\mathcal{E} 1$ spent on fundraising (marketing and advertising), and trends in trading income (ie sales of charity branded products)). ${ }^{35-41}$ The two key ratios, however, according to Hyndman, ${ }^{43}$ are administration costs as a percentage of total expenditure (ACE) and fundraising costs as a percentage of total expenditure, 
as these are (allegedly) the most important pieces of information demanded by donors. Numerous empirical studies have reached this conclusion, both in Britain ${ }^{43}$ and the USA. $^{44}$ As an example of the salience of these particular ratios, Margolis ${ }^{45}$ noted the alarmingly damaging effects on the fundraising capacity of the National Society for the Prevention of Cruelty to Children of the adverse publicity surrounding the revelation in 19992000 that it was spending more on fundraising and administration than on helping children. The ratio of spending on charity programmes to total resources has also received attention ${ }^{46-48}$ on the grounds that donors may be put off by the sight of charities accumulating large amounts of cash reserves instead of spending all their donor income on beneficiaries.

\section{COMPLEX NATURE OF CHARITY EFFICIENCY}

Baber et al. ${ }^{49}$ pointed out that the values of all the above mentioned ratios would depend critically on the strategic

positioning of the charity in question, its activities, rate of growth, objectives and current investments. ${ }^{50}$ Moreover, certain inputs (such as voluntary labour) and outputs (eg improvements in beneficiaries' feelings about themselves) could not normally be quantified. Also disparate charities often performed functions with quite different characteristics. ${ }^{51,52}$ Service provision in particular generates extensive ancillary administrative costs. ${ }^{53,54}$ Steinberg complained that (negative) public reactions to a charity spending much of its income on administration were irrational and an 'anomaly' because fundraising costs were 'sunk' and thus should not enter a donor's decision to support a given charity. ${ }^{55}$ Another consideration was that a charity might have as one of its core objectives the raising of public awareness of a social or medical issue, thus necessitating large-scale expenditures on advertising and promotion. ${ }^{56,57}$

\section{NEED FOR EFFECTIVE PUBLICITY}

Ormstedt ${ }^{53}$ accused the media of fermenting public misunderstanding of the realities of charity costs. It followed that the wide dissemination of accurate information on these matters was essential. Saxon-Harrold ${ }^{59}$ similarly concluded that charities needed continuously to emphasise that operating costs were kept to a minimum and that a high proportion of donations reached the projects for which they were intended. Much media speculation about charity inefficiency, according to Fenton et al., was 'premised on hearsay', and people 'make constant demands for more authoritative information on the efficiency of charities'. ${ }^{60}$ Thus it was a relatively simple matter to 'put the record straight'.

\section{TRAIT COVARIATION}

People observe the behaviour of charities directly (gaining information from media reports, charity promotional materials and personal experience), or draw information about them from their memories. Thus, for example, an individual may have a residual memory that equates high administrative expenditure with incompetent bureaucracy, high advertising expenditures with waste, and so on. In general, information recovered from memory may or may not be accurate, and some will almost certainly be inferred. Chaiken, Wyer and Srull and others have suggested that people often 
employ cognitive shortcuts when drawing inferences. ${ }^{61-64}$ Moreover, according to Mason et al., they frequently apply 'attribute-relationship schemata ${ }^{65}$ to their conjectures whereby they 'infer performance on one attribute from accessible information on another attribute'. Mason et al. cited the example of a consumer assuming that high price means high quality or that a big engine in a motor car is associated with superior acceleration and shorter braking distance, even though such inferences are frequently incorrect.

The proposition that a person's perceptions of an entity's attributes in one respect will correlate significantly with his or her assumptions regarding its attributes in other respects is known as the 'trait covariation' hypothesis. ${ }^{67,68}$ This maintains that people perceive entities in terms of bundles of characteristics which they assume go together, despite the absence of confirmatory evidence. A 'central trait' is one that the perceiver associates with many others and thus is seen as especially meaningful and predictive. Hence the person is likely to move quickly from information received about a central trait to inferences about the entity in general. Support for the trait covariation hypothesis derives from research in psychological perception that (allegedly) has revealed that impressions are formed very quickly, that memories of an entity are a vital determinant of current attitudes towards it, and that a favourable or unfavourable interpretation in one context extends to other situations and to other seemingly unrelated characteristics. ${ }^{69}$ Inferences interconnect and, according to the hypothesis, persist long after the information upon which they are based has ceased to be relevant. ${ }^{70}$ Forgas $^{71}$ in particular suggested that the 'how do I feel about something' heuristic was commonly used by individuals as a general proxy for a variety of real or imagined characteristics when deciding whether to adopt positive or negative interpretations.

\section{ACCURACY OF INFERENCES}

Mason et al. ${ }^{72}$ suggested that a person's mental picture of which attributes went together (ie his or her attributerelationship schemata) would be heavily influenced by the individual's past knowledge of and familiarity with the entity in question. This knowledge could be relevant or irrelevant. The more relevant the past knowledge, Mason et al. argued, the more accurate would be a person's evaluations of the entity as a whole, its specific attributes, and the relationships between those attributes. They noted however that information drawn from memory was less likely to be relevant and hence might lead to inaccurate assessments.

In general, the more a person is knowledgeable about and familiar with an entity the better developed will be his or her mental structures for identifying attributes that are particularly pertinent to that entity. ${ }^{73}$ Thus, high levels of knowledge and familiarity enable the individual to encode, categorise, interpret and recall appropriate information about attributes more easily and to be more discerning when making attribute inferences. If knowledge and familiarity are low, conversely, the person is likely to employ poorly developed heuristics and to process information 'peripherally', without careful thought or elaboration. This could result in the individual being heavily influenced by surface characteristics in order to relieve the cognitive effort needed to arrive at judgments. $^{74}$ Mason and Bequette ${ }^{75}$ cited a large number of empirical studies which concluded that inferences 
are likely to be less accurate in these conditions.

Attribute-relationship theory also predicts that the presentation to an individual of small amounts of true and relevant information about an entity immediately prior to the person making judgments about it will affect the accuracy of these judgments across a diverse range of attributes. Critically, the elements of relevant information proffered need not impinge directly on the attributes being evaluated. Thus, for example, Mason and Bequette found that consumers' estimates of the braking and acceleration performances of various models of motor car were significantly more accurate among people who were given information on the fuel economy and price of these models, notwithstanding the fact that none of these variables need be linked. Even the provision of marginally relevant information can result in large improvements in the accuracy of assessments. Attribute relationship theory explains this phenomenon in terms of the (marginally) relevant cues acting as stimuli that engender much higher levels of cognitive effort and deeper mental processing vis-à-vis the attributes to be inferred. ${ }^{76,77}$ Thinking about the cues activates aspects of memory that otherwise would lie dormant ${ }^{78}$ and encourages rationality and serious consideration of the issues involved. ${ }^{79}$ In the absence of relevant cues, superficial responses might occur. ${ }^{80}$

\section{THE INVESTIGATION}

The study examined the accuracy with which a sample of members of the public rated certain performance attributes of a set of UK charities. It assessed the influence of (i) the provision of relevant or irrelevant information, and (ii) the depth of a person's knowledge of and familiarity with charities on the accuracy of ratings, and explored the respondents' perceptions of how various efficiency attributes covaried.

Additionally, the study investigated the relationships between a person's ratings of a charity's efficiency and the degree of favourability of his or her assumptions about its work in general. The research employed measures of charity efficiency that prior literature has identified as being particularly relevant to the issue. ${ }^{81-84}$ This is not meant to imply that these measures actually reflect charity efficiency, only that there exists a substantial body of evidence to suggest that the general public thinks that this is the case. ${ }^{85-87}$ The appropriate measures are:

- the ratio of administration costs to expenditure (ACE) $\left(\right.$ Paton $^{88}$ noted how ACE ratios were increasingly analysed and reported by UK newspapers);

- the ratio of fundraising costs (advertising, marketing, etc.) to expenditure (FCE). To help the participants in the study make their predictions of FCE and ACE quickly and easily they were invited to tick off one of nine options: less than 5 per cent; 6 to 10 per cent; 11 to 20 per cent; etc, through to 'more than 70 per cent';

- the ratio of the annual amount transferred to reserves to annual income (on the basis that previous studies have found that donors do not like the idea of charities raising money from the general public and not spending it);

- the ratio of income from trading (sales of charity branded products) to total income (on the assumption that a high value for this item is regarded as indicating effective management and a progressive approach to fundraising). 
As a check on the applicability of the above measures, 19 ratios or other directly comparable items of information concerning charity performance (including these four) available from the standard format used by charities to present their accounts ${ }^{87}$ were listed and were presented to a group of 29 part-time postgraduate students who were asked to rank them in terms of their perceived relevance to charity efficiency and performance. The rank order that emerged was confirmed via street interviews with 20 members of the general public. The same items appeared in the list of the top ten indicators in both cases, and the top six contained the four previously mentioned ratios.

Four charities were selected for the investigation taken from a list of the ten best known charities in the UK (as identified by previous studies ${ }^{88-90}$ ). The charities concerned were Oxfam, the National Society for the Prevention of Cruelty to Children (NSPCC), the Royal Society for the Prevention of Cruelty to Animals (RSPCA) and Macmillan Cancer Relief. Thus, four quite different charity sectors were represented: Third World development, children, animals and health care.

\section{MEASURING THE ACCURACY OF PERCEPTIONS}

The study followed Mason et al. ${ }^{91}$ in applying Cronbach's approach to the assessment of the accuracy of a person's ratings of the various performance attributes of a set of objects (charitable organisations in the present case). To understand Cronbach's methodology, suppose that an individual rates the administration cost to expenditure (ACE) ratio of the first of the four charities in the set (the RSPCA, say) at a particular level. Then the person rates each of the three remaining RSPCA performance measures. These ratings can be averaged to give a number $\left(\bar{R}_{i}\right)$ representing the mean of that individual's ratings across the four attributes for charity ' $i$ ' (the RSPCA in this instance). Let $\bar{R} A l l$ denote the 'grand mean' of the person's ratings of all four attributes in all four of the charities. Hence $\left(\bar{R}_{i}-R A l l\right)$ shows the difference between the individual's rating of the performance of the RSPCA and what he or she expects for the four charities in general. This can now be compared with the difference between the actual value of the mean of the four performance measures of the RSPCA $\left(\bar{A}_{i}\right)$ and the actual grand mean of the performance figures averaged across all the $(n)$ charities (where $n=4$ in this case) in the group $(\bar{A} A l l)$, viz:

$\left(\left[\left(\bar{R}_{i}-\bar{R} A l l\right]-\left[\left(\bar{A}_{i}-\bar{A} A l l\right]\right)\right.\right.$. Thus the accuracy of a person's perceptions of the relative performance of the RSPCA compared to the other charities may be assessed. For example, the RSPCA might be seen as performing 10 per cent better than the all sample average, whereas in reality the RSPCA might be only 3 per cent better, giving an accuracy misjudgment of 7 per cent.

This exercise may now be repeated for the second charity (OXFAM for instance), and then for the third and the fourth. The results can be averaged across the four charities to give an overall measure of how accurately the person perceives the efficiencies of these four charities. Cronbach referred to this overall measure as 'differential elevation' (DE).

$$
(D E)^{2}=\frac{1}{n} \sum_{i=1}^{n}\left(\left[\bar{R}_{i}-\bar{R} A l l\right]-\left[\bar{A}_{i}-\bar{A} A l l\right]\right)^{2}
$$

The numbers inside the main brackets are squared to make all the differences 
positive. Otherwise the positive and negative deviations could cancel each other out, defeating the object of the exercise.

Cronbach next introduced the notion of 'differential accuracy' (DA), which focused on the accuracy of an individual's perceptions of attributes (in this case performance measures) rather than organisations. To illustrate, let $R_{i j}$ represent a person's rating of the first attribute (say the ACE ratio) of the first charity (eg the RSPCA). Let $\bar{R}_{j}$ denote the grand mean of the individual's ratings of the ACE ratios of all the four charities, so that the gap:

$$
\left(R_{i j}-\bar{R}_{j}\right)-\left(\bar{R}_{i}-\bar{R} A l l\right)
$$

represents the person's guess of whether the RSPCA's ACE ratio is better or worse than the ACE ratios of all the charities in the group, and how this compares with the individual's perception of the RSPCA's overall average performance $\left(\bar{R}_{i}\right)$ relative to the overall average performance of the group as a whole. For example, the person might think that the RSPCA's ACE ratio is 5 per cent better than the average ACE ratio for the set (ie $R_{i j}-\bar{R}_{j}=0.05$ ), whereas the individual may believe that the RSPCA is 10 per cent more efficient overall than the group average (ie $\left.\bar{R}_{i}-\bar{R} A l l=0.1\right)$. Hence the RSPCA's ACE ratio is seen as relatively poor compared to the RSPCA's other performance measures. These figures can now be compared with the true values. If this exercise is repeated for the second efficiency measure (eg the FCE ratio), the third and so on, for each of the four charities and the results are averaged, a figure will emerge representing the accuracy of the person's evaluations of specific attributes of charities compared to expectations regarding attributes as a whole. The relevant formula, where there are ' $k$ ' attributes and $\bar{A}_{i j}$ and $\bar{A}_{j}$ denote true values, is:

$$
\begin{aligned}
(D A)^{2}= & \frac{1}{k n} \sum_{i=1}^{n} \sum_{j=1}^{k}\left(\left[R_{i j}-\bar{R}_{j}-\bar{R}_{i}+\bar{R} A l l\right]\right. \\
& \left.-\left[A_{i j}-\bar{A}_{j}-\bar{A}_{i}-\bar{A} A l l\right]\right)^{2} .
\end{aligned}
$$

In summary, DE shows how accurately a person rates the average performance of the four charities taken as a group, while DA measures how accurately, on average, the person evaluates specific measures of efficiency. ${ }^{92}$ DE reflects how good the person is at rating organisations; DA shows the person's ability to rate attributes.

\section{MEASURES OF COVARIANCE}

In order to assess the accuracy of the respondent's assumptions regarding which attributes went together (covaried) the person was asked the question 'If a relatively large proportion of a charity's total expenditures are spent on administration, how likely is it that a relatively large proportion of its expenditures will be on marketing and advertising and other fundraising activities?', followed by similar items relating ACE to income per employee, the proportion of revenues going into reserves and the trading to total income ratio. A further question was worded: "If a charity is expanding its income and activities at a high rate of growth, how likely is it that it will be devoting a relatively large proportion of its expenditures to administration?' This was repeated to relate growth to perceptions concerning relative fundraising costs, administration cost per employee, reserve accumulation and trading income. Responses were recorded on four point scales: very likely, likely, unlikely, very unlikely. Accuracy was measured by calculating the differences between the correlations inferred from the 
Table 1: Charity knowledge and familiarity

1 Please rate your knowledge about charities.

2 Relative to people you know, how would you rate your knowledge of charities?

3 Based on your current knowledge about charities, how comfortable would you feel about making a very large donation to a charity?

4 How much information about charities have you been exposed to during your lifetime?

5 How familiar are you with the activities of charities?

respondents' answers and the true correlations among these variables computed from the data available in the Charities Direct database (Caritas Data Ltd) for the UK's top ten fundraising charities in each of the four sectors covered by the study (40 charities in all).

The study also attempted to establish respondents' inferences of relationships between perceived charity efficiency and other important assumptions about charities. Bennett and Gabriel's ${ }^{93}$ study of the organisational images causing the public to admire a charity identified five major factors associated with strong admiration, ie achievement ('getting things done'), being 'well-managed', 'providing an excellent service', 'caring and compassion' and 'idealism'.

Accordingly the respondents were asked the questions: 'If a relatively large proportion of a charity's expenditure is on administration, how likely is it that the charity will (i) be well-managed', etc. for the five attributes. The five items were then repeated but with 'expenditure on marketing advertising and other fundraising activities' replacing the words 'expenditure on administration'. Four-point scales ( 4 = very likely, $3=$ likely, $2=$ unlikely, $1=$ very unlikely) were employed in all instances.

\section{KNOWLEDGE, FAMILIARITY AND INFORMATION}

A person's knowledge of and familiarity with charities was measured via the five items listed in Table 1, which are based on the 'Product Experience' inventory developed from previous studies by Mason et al..$^{94}$ All items were scored using five-point scales, eg $5=$ very knowledgeable, $1=$ very unknowledgeable for items (1) and (2); $5=$ very comfortable, $1=$ very uncomfortable for item (3). Five pieces of relevant information on each of the four charities were given to half the sample (see below); five items of irrelevant information were provided to the rest. The relevant information consisted of six items identified from the previously mentioned 19 pieces of information as having the potential to induce a person to think more deeply and constructively about the items to be inferred and to help structure the individual's cognitive approaches to the task. These were the rate of growth of the charity's income, the rate of growth/decline of income per employee, the proportion of a charity's workforce earning more than $£ 50,000$ a year (a figure that all large charities are legally required to provide), the rate of change in the charity's income for each $f_{1} 1$ spent on marketing, and the ratios of (i) revenues from investments and (ii) salary costs, to total annual income. The purpose of these prompts was to give the respondents items of information pertinent to the stated indices of charity performance that would induce careful and rational thought about the other matters, but without making the answers to subsequent questions trivially obvious. ${ }^{95}$ They were chosen by asking the same group of 29 part-time 
postgraduate students that ranked the relevance of the 19 items vis-à-vis charity efficiency to rank ten remaining items (four of the 19 were to be inferred and five were patently inappropriate) in terms of their relevance to 'how people might think' about the inferred ratios.

The sorts of inference that respondents could (possibly) draw from the information provided might include the assumption that a high growth rate is associated with relatively high marketing expenditures and high transfers to reserves, that low levels of spending on staff salaries are indicative of a relatively low ACE ratio, and so on. Information regarding rates of change was worded in simple terms, eg 'this charity's income has grown by $\mathrm{X}$ per cent on average each year over the last three years', and 'if you work out how much income the charity receives for each $f_{1} 1$ it spends on marketing, this figure has increased by $\mathrm{X}$ per cent on average each year over the last three years'. The irrelevant information (ie facts not expected to induce inferences) that were given to the remaining 50 per cent of the sample comprised the year of establishment of the charity, the name of its patron or chief executive officer, its registered address and the number of people on its Board of Trustees.

A final section of the questionnaire asked (five-point scales: $5=$ strongly agree, $1=$ strongly disagree) whether the respondent believed that 'charities provide very good value for money', whether his or her overall opinion of charities was 'very favourable' and whether a low ACE ratio was thought to be associated with very large charities (ie whether economies of scale were presumed to exist). It also requested details of the person's gender, age category and how much on average the respondent donated to charity each month.

\section{RESEARCH PROCEDURES}

Four groups of people were used for the study: 71 administrative staff at the authors' home university (from a sampling frame of 211 people); 49 members of the academic faculty of the same university (representing 24.5 per cent of the teaching staff in two large departments); 66 part-time postgraduate students (all of whom were in full-time employment); and 100 members of the general public approached at random and interviewed in street locations around three railway and underground (metro) stations in central London. Respondents within the university completed a hard copy questionnaire. Sixty-two per cent of the aggregate 286-strong sample was male. The response patterns of the four groups were compared, no significant disparities relevant to the present study emerging. Hence the 286 sets of responses were analysed collectively.

The participants were first questioned about their knowledge of and familiarity with charities (see Table 1) and then given relevant or irrelevant attribute information. Participants next rated each charity on each of the attributes previously described and answered the items concerning assumed covariances. Half of the questionnaires distributed within the university contained relevant information and half irrelevant information. The two versions were well shuffled prior to circulation. Participants were informed that the facts they were given came from 'The Government Charity Commission and other official sources'. Circumstantially, exactly half of the returns were in the relevant information category. For the street interviews the interviewers (the authors plus market research students who had been fully briefed on appropriate interview procedures) alternated the version of the questionnaire presented to the respondents. 


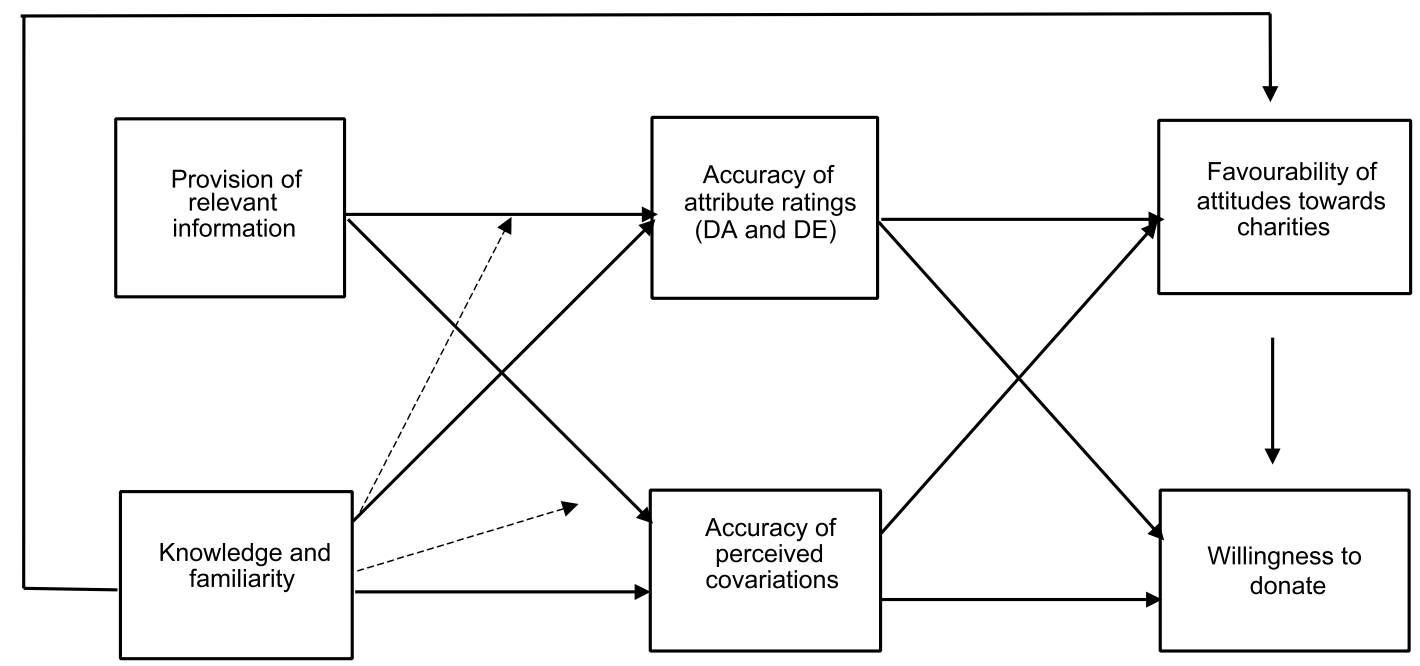

Figure 1 The model

\section{THE MODEL}

A priori it was anticipated that the provision of relevant information to a person and his or her possession of extensive knowledge about charities would improve the accuracy of the person's ratings of charity attributes (DA), overall charity performances with respect to these attributes (DE) and the covariances among attributes. It seemed reasonable to suppose, moreover, that high levels of knowledge and familiarity would moderate the influence of the provision of relevant information on the accuracy of ratings (ie it was presumed that the impact of this variable would be stronger among people who were knowledgeable about and familiar with charities). Accurate perceptions were assumed to induce favourable attitudes towards charities (a variable that might also be affected by a person's knowledge and familiarity) and a greater willingness to donate. The suggested model is shown in Figure 1.

In order to be able to estimate this model, DA and DE were calculated directly and the variable for the 'accuracy of assumptions regarding covariances' (ie the measurable covariances rather than the covariances involving subjective attitudes towards charities) was computed as the mean average for each respondent. The five items of the knowledge and familiarity instrument were factor analysed, a univariate solution emerging $(\lambda=3.7, \alpha=0.85)$. (Univariability was confirmed via a comparison with two and three factor alternatives via the AMOS 4 package.) Hence the five items were composited into a single scale. The two items concerning general attitude towards charity (favourability and whether charities offered good value for money) were highly correlated $(R=0.72)$ and thus were combined. Individuals in the 50 per cent of the sample who received relevant information were coded at value one, the remainder at value zero. The moderators were mean squared to minimise statistical problems arising from multicollinearity.

\section{RESULTS}

On the average, the respondents believed that around 30 per cent of each charity's expenditures went on administration, that 
Table 2: Attribute ratings and perceived covariances

\begin{tabular}{lll}
\hline & Beta coefficient & Critical ratio \\
\hline $\mathrm{RI} \rightarrow \mathrm{DA}$ & -0.22 & 1.98 \\
$\mathrm{RI} \rightarrow \mathrm{DE}$ & -0.14 & 1.10 \\
$\mathrm{RI} \rightarrow \mathrm{APC}$ & -0.19 & 2.01 \\
& & \\
$\mathrm{~K} \& \mathrm{~F} \rightarrow \mathrm{DA}$ & -0.34 & 3.19 \\
$\mathrm{~K} \& \mathrm{~F} \rightarrow \mathrm{DE}$ & -0.30 & 2.72 \\
$\mathrm{~K} \& \mathrm{~F} \rightarrow \mathrm{APC}$ & -0.36 & 6.92 \\
$\mathrm{~K} \& \mathrm{~F} \rightarrow \mathrm{FAC}$ & 0.79 & 7.79 \\
& & \\
$(\mathrm{RI}) \times(\mathrm{K} \& \mathrm{~F}) \rightarrow \mathrm{DA}$ & -0.12 & 3.90 \\
$(\mathrm{RI}) \times(\mathrm{K} \& \mathrm{~F}) \rightarrow \mathrm{DE}$ & -0.09 & 4.11 \\
$(\mathrm{RI}) \times(\mathrm{K} \& \mathrm{~F}) \rightarrow \mathrm{APC}$ & -0.13 & 4.77 \\
\hline
\end{tabular}

about 20 per cent was spent on fundraising and that 6 per cent went into reserves. These figures match closely those reported by earlier investigations of these matters. ${ }^{96-98}$ Thus, as in prior studies, the typical respondent thought that only a minority (46 per cent in the present instance) of the average charity's expenditures actually reached beneficiaries. In reality, the average expenditure on administration for the four charities considered was a little below 9 per cent of total spending; mean expenditure on marketing, advertising and other promotions was 7 per cent, and just 1.6 per cent was put into reserves. The average self-reported monthly charity donation level was $f 3$ to $\mathcal{E}^{4}$, again replicating the findings of previous investigations (and suggesting that the members of the sample were not unrepresentative of the British donating public).

The model shown in Figure 1 was estimated using the AMOS 4 package (SPSS Ltd.). Overall the model performed well $\left(\chi^{2}[18 \mathrm{df}]=24.14\right.$, $p=0.85$; GFI $=0.89$; AGFI $=0.85)$.

Table 2 presents the results concerning the effects of relevant information provision (RI) and knowledge and familiarity $(\mathrm{K} \& \mathrm{~F})$ on $\mathrm{DA}, \mathrm{DE}$ and the accuracy of perceived covariances (APC). It also shows the strength of the link between K\&F and the favourability of the respondent's attitudes towards charities (FAC) and the influences of the moderators. The provision of relevant information significantly improved a person's ability to rate charity performance attributes accurately (DA) and to predict covariances among these attributes, although it failed to help people rate individual charities in terms of these attributes (DE). Possession of high levels of knowledge about and familiarity with charities exerted positive and significant impacts on all three of the accuracy variables, and represented a highly significant moderating influence on the effects of the provision of relevant information. Hence the supply of relevant information had a more powerful effect on the accuracy of predictions if the person was knowledgeable about and very familiar with charities.

Table 3 lists the impacts of ratings accuracy and APC on FAC and willingness to donate (WD) (ie the self-reported average amount donated to charity each month). It is evident from Table 3 that people who guessed performance attribute (DA) relatively accurately held more favourable attitudes towards charities than others, and were more likely to donate. The same was true of individuals who made relatively 
Table 3: Attitudes towards charities and willingness to donate

\begin{tabular}{lll}
\hline & Beta coefficient & Critical ratio \\
\hline $\mathrm{DA} \rightarrow$ FAC & -4.92 & 4.21 \\
$\mathrm{DE} \rightarrow$ FAC & -3.13 & 2.29 \\
$\mathrm{DA} \rightarrow$ WD & -2.97 & 2.02 \\
$\mathrm{DE} \rightarrow$ WD & -3.14 & 2.14 \\
& & \\
$\mathrm{APC} \rightarrow$ FAC & -4.0 & 3.71 \\
$\mathrm{APC} \rightarrow$ WD & -2.4 & 2.03 \\
\hline
\end{tabular}

accurate assessments of the overall performance of each charity (DE). Respondents with a 'good feel' for which performance attributes went together were also more favourably inclined towards charities and more willing to give.

An examination of the results in greater detail revealed that although the respondents were on the average very inaccurate in their ratings of attributes (the mean difference between estimates and reality was 37 per cent), the assessments of the people who were given relevant information was substantially less inaccurate than the rest (the mean difference was 26 per cent among this group). In general, ratings of attributes were significantly more accurate than evaluations of the performances of charities (DA had a mean of 0.34 , the mean for DE was 0.41 , the difference was significant at the 0.01 level). This result is compatible with research findings in the commercial world concerning customers' ratings of the attributes of products. ${ }^{99}$ In contrast to the imprecision of the respondents' assessments of DA and DE, their predictions of attribute covariances were quite reasonable. For example, the true correlation between ACE and FCE for the 40-strong sample of charities was 0.44 , and 66 per cent of the respondents believed that it was 'likely' that a high ACE was associated with a high FCE. The true correlation between FCE and income per employee was 0.4. Sixty-four per cent of the respondents thought it was likely that a charity with a high FCE would also be relatively high in terms of income per employee. Similarly accurate predictions applied to the correlations between growth and (i) FCE (66 per cent of the respondents guessed this reasonably well), (ii) reserve accumulation (58 per cent) and (iii) trading income (55 per cent).

\section{ACE, FCE AND ATTITUDES TOWARDS CHARITIES}

Table 4 gives the inferred covariances that were believed to exist between a charity's ACE and FCE ratios and (subjective and unmeasurable) organisational characteristics. The outcomes confirm the results of previous studies which concluded that the general public dislikes the idea of charities spending relatively large amounts on administration and fundraising. The mean response value fell within the 'unlikely' category for all five of the quality of service items ([a] to [e]), although animosity towards high FCE ratios was less pronounced. Moreover the respondents believed on average that it was 'likely' that a charity with high ACE and FCE ratios would be very large. Thus the participants did not think that large charitable organisations enjoyed economies of scale in administration. No differences with respect to age or gender could be discerned in relation to this matter, or indeed to any other aspect of the analysis. 
Table 4: Inferred covariances

\begin{tabular}{lll}
\hline & \multicolumn{2}{l}{ Mean value } \\
\cline { 2 - 3 } The charity & ACE & FCE \\
\hline (a) Is well managed & 2.2 & 2.4 \\
(b) Gets things done & 2.2 & 2.8 \\
(c) Provides an excellent service & 2.1 & 2.1 \\
(d) Is caring and compassionate & 2.5 & 2.4 \\
(e) Is idealistic & 2.0 & 2.6 \\
(f) Is very large & 3.1 & 3.3 \\
\hline
\end{tabular}

Four-point scale: 4 = very likely, 1 = very unlikely that a high ACE or FCE ratio is associated with the relevant characteristic.

\section{CONCLUSION}

The results are compatible with the findings of academic studies completed in the field of consumer behaviour which concluded that the provision of small amounts of relevant information about a product in relation to just a couple of its characteristics has the potential to improve the accuracy of a person's ratings of the product across a wide range of disparate attributes. It seems that the information proffered stimulates cognitive effort vis-à-vis these wider matters and engenders rational thought concerning possible magnitudes. In the absence of such cues the person is liable not to bother thinking at all about what might represent a reasonable figure and instead make a 'wild guess' casually and superficially. Consideration of one or two pieces of relevant information causes the individual to think properly about sensible upper and lower bounds for the value of the attribute in question. Moreover, participants given relevant information were better able to predict which attributes 'went together' than were the rest of the sample.

Clearly the outcomes to the present investigation underscore the need for charities to state the facts regarding the proportions of their expenditures that are devoted to administration and fundraising, and to broadcast these facts vigorously and extensively. It appears that the supply of even a limited amount of information about a charity's efficiency can exert powerful influences on donors' beliefs about a variety of the organisation's attributes. Unfortunately, from the charity management point of view, the respondents tended to assume as a matter of course that relatively high levels of expenditure on administration and fundraising were 'bad' and by implication incompatible with the attainment of philanthropic objectives. Accordingly, charities must seek to educate the public in respect of these matters, eg by explaining that 'campaigning' to raise awareness of and hence help alleviate a problem (child abuse, cruelty to animals, etc.) is a valuable activity in and of itself. In the words of Sargeant et al., 'there needs to be a strong educational component to any promotional campaign' in order to counteract the feeling that charities are well meaning but inefficient. ${ }^{100}$

A person's general knowledge about and familiarity with charities was a highly significant determinant of how favourably the individual felt about charities and how accurately he or she rated their performance attributes. This reinforces the proposition that charities should publicise their work and operational details as widely as possible. Indeed, it arguably justifies charities incurring substantial spending on public relations, image building and reputation management in order to create accurate 
perceptions of their activities. Further research is required into the exact media and promotional mechanisms that are most effective for achieving such objectives. Additional research is also necessary into whether disparate types of people hold different perceptions of the levels of charity ACE and FCE ratios. The questionnaire employed in the current investigation was quite long and it was not possible to explore this particular matter, other than asking for the participant's age and gender (neither of which exerted significant influences on outcomes). It would be useful to relate respondents' assumptions concerning ACE and FCE ratios to their educational backgrounds, income levels, occupation, ethnicity and to psychographic and sociocultural variables.

\section{References}

1 Cronbach, L. (1955) 'Processes affecting scores on "understanding of others" and "assumed similarity", Psychological Bulletin, Vol. 52, No. 2, pp. 177-193.

2 Saxon-Harrold, S., Carter, J. and Humble, S. (1987) 'The charitable behaviour of the British people: A survey of patterns and attitudes to charitable giving', Charities Aid Foundation, Tonbridge.

3 Harvey, J. and McCrohan, K. (1988) 'Fundraising costs: Societal implications for philanthropies and their supporters', Business and Society, Vol. 27, No. 1, pp. 15-22.

4 Posnett, J. (1989) 'Determinants of household giving to charity in the UK', in Lee, N. (ed.) 'Sources of charity finance', Charities Aid Foundation, Tonbridge.

5 Fenton, N., Golding, P. and Radley, A. (1993) 'Thinking about charity: Report of a pilot study into public attitudes to charities and volunteering', in Saxon-Harrold, S. and Kendall, J. (eds) 'Researching the voluntary sector', Charities Aid Foundation, Tonbridge, pp. 75-86.

6 Glaser, J. (1994) 'The United Way scandal: An insider's account of what went wrong and why', John Wiley and Sons, New York.

7 Warwick, M. (1994) 'Raising money by mail: Strategies for growth and financial stability', Strathmoor Press, Berkeley CA.

8 Schlegelmilch, B., Diamantopoulos, A. and Love, A. (1997) 'Characteristics affecting charitable donations: Empirical evidence from Britain', Journal of Marketing Practice: Applied Marketing Science, Vol. 3, No. 1, pp. 14-28.

9 Bennett, R. and Gabriel, H. (2000) 'Image building for charity organisations', Social Marketing Quarterly, Vol. 6, No. 3, pp. 77-81.

10 Sargeant, A., Ford, J. and West, D. (2000) 'Widening the appeal of charity', International Journal of Nonprofit and Voluntary Sector Marketing, Vol. 5, No. 4, pp. 318-332.

11 Hyndman, N. (1990) 'Charity accounting: An empirical study of the information needs of contributors to UK fundraising charities', Financial Accountability and Management, Vol. 6, No. 4, pp. 295-307.

12 Fenton et al. (1993) op cit.

13 Sargeant et al. (2000) op cit.

14 Steinberg, R. (1986) 'Should donors care about fundraising?' in Rose-Ackerman, S. (ed.) 'The economics of non-profit institutions: Studies in structure and policy', Oxford University Press, New York, pp. 347-364.

15 Bailey, A. and Bruce, M. (1992) 'United Way: The fallout after the fall', Chronicle of Philanthropy, March, pp. 2-6.

16 Ormstedt, D. (1994) 'Government regulation of fundraising: A struggle for efficacy', New Directions for Philanthropic Fundraising, Vol. 3, pp. 129-141.

17 Greenlee, J. and Gordon, T. (1997) 'The impact of professional solicitors on fund raising in charitable organisations', in Proceedings of the 1997 ARNOVA Conference, Association for Research in Non-profit and Voluntary Associations, Indianapolis.

18 Sargeant, A. (1999) 'Charitable giving: Towards a model of donor behaviour', Journal of Marketing Management, Vol. 15, No. 4, pp. 215-238.

19 Omisakin, I. (1997) 'Value for money in the charity sector', Management Accounting, Vol. 75, No. 3, pp. 56-58.

20 Palmer, P. and Vinten, G. (1998) 'Accounting, auditing and regulating charities: Towards a theoretical underpinning', Managerial Auditing Journal, Vol. 13, No. 6, pp. 346-355.

21 Tinkelman, D. (1998) 'Differences in sensitivity of financial statement users to joint cost allocations: The case of non-profit organisations', Journal of Accounting, Auditing and Finance, Vol. 13, No. 4, pp. 377-394.

22 Paton, R. (2002) 'Aces high: Charity administration costs', Financial Management, July/August 2002, pp. 40-42.

23 Ibid.

24 Hyndman, N. and McKillop, D. (1999) 'Conversion ratios in charities in England and Wales: An investigation of economies of scale', Financial Accountability and Management, Vol. 15, No. 2, pp. 135-154.

25 Sergeant et al. (2000) op. cit., p. 322.

26 Saxon-Harold et al. (1987) op. cit.

27 Warwick (1994) op. cit.

28 Sergeant et al. (2000) op. cit.

29 Paton (2002) op. cit. 
30 Harvey and McCrohan (1988) op. cit.

31 MORI (1995) 'Committed Givers: Study for CAF', MORI Ltd, London.

32 Bennett and Gabriel (2000) op. cit.

33 Fenton et al. (1993) op. cit., p. 77.

34 Ibid., p. 78.

35 Omisakin (1997) op. cit.

36 Tinkelman (1998) op. cit.

37 Paton (2002) op. cit.

38 Hyndman and McKillop (1999) op. cit.

39 Margolis A. (2001) 'Causes and effects', Financial Management, March, pp. 18-22.

40 Wise, D. (2001) 'Give and make: Charity performance', Financial Management, March, pp. 21-24.

41 Chaiken, S. (1980) 'Heuristic versus systematic information processing and the use of source versus message cues in persuasion', Journal of Personality and Social Psychology, Vol. 39, No. 2, pp. 752-766.

42 Hyndman (1990) op. cit.

43 Ibid.

44 Tinkelman (1998) op. cit.

45 Margolis (2001) op. cit.

46 Ibid.

47 Baber, W., Roberts, R. and Visvanathan, G. (2001) 'Charitable organisations' strategies and programme-spending ratios', Accounting Horizons, Vol. 15, No. 4, pp. 329-344.

48 Wise (2001) op. cit.

49 Baber et al. (2001) op. cit.

50 Margolis (2001) op. cit.

51 Hyndman and McKillop (1999) op. cit.

52 Wise (2001) op. cit.

53 Paton (2002) op. cit.

54 Margolis (2001) op. cit.

55 Steinberg (1986) op. cit., p. 351.

56 Glaser (1994) op. cit.

57 Margolis (2001) op. cit.

58 Ormstedt (1994) op. cit.

59 Saxon-Harrold et al. (1987) op. cit.

60 Fenton et al. (1987) op. cit., p. 77.

61 Chaiken (1980) op. cit.

62 Wyer, R. and Srull, T. (1989) 'Memory and cognition in its social context', Lawrence Erlbaum, Hillsdale NJ.

63 Taylor, S., Peplau, L. and Sears, D. (1994) 'Social psychology', eighth edition, Prentice-Hall, Englewood Cliffs NJ.

64 Aronson, E., Wilson, T. and Akert, R. (1997) 'Social psychology', second edition, Longman, New York.

65 A schemata is an 'organised, structured set of cognitions, including some knowledge about the object, some relationships among the various cognitions, and some specific examples' (Taylor et al. (1994) op. cit., p. 50). Schemata facilitate the simplification, organisation and processing of complex bodies of information. They help the person to remember detail, to fill gaps in knowledge and to interpret and evaluate information about an entity.
66 Mason, K., Jensen, T., Burton, S. and Roach, D. (2001) 'The accuracy of brand and attribute judgements: The role of information relevancy, product experience, and attribute-relationship schemata', Journal of the Academy of Marketing Science, Vol. 29, No. 3, pp. 307-317.

67 Hamilton, D. (1989) 'Understanding impression formation: What has memory research contributed?' in Solomon, P., Goethals, G., Kelley, C. and Stevens, B. (eds) 'Memory: Interdisciplinary approaches,' Springer-Verlag, New York, pp. 221-242.

68 Bennett, R. and Gabriel, H. (2001) 'Corporate reputation, trait covariation and the averaging principle: The case of the UK pensions mis-selling scandal', European Journal of Marketing, Vol. 35, No. 3/4, pp. 387-413.

69 Taylor et al. (1994) op. cit.

70 Bennett and Gabriel (2001) op. cit.

71 Forgas, J. (1995) 'Mood and judgement: The affect intrusion model', Psychological Bulletin, Vol. 117, pp. 39-66.

72 Mason et al. (2001) op. cit.

73 Omisakin (1997) op. cit.; Tinkelman (1998) op. cit.; Paton (2002) op cit.; Hyndman and McKillop (1999) op. cit.; Margolis (2001) op cit.; Wise (2001) op. cit.; Chaiken (1980) op. cit.

74 Aronson et al. (1997) op. cit.

75 Mason, K. and Bequette, J. (1998) 'Product experience and consumer product attribute inference accuracy', Journal of Consumer Marketing, Vol. 15, No. 4, pp. 343-357.

76 Chaiken (1980) op. cit.

77 Wyer and Srull (1989) op. cit.

78 Aronson et al. (1997) op. cit.

79 Forgas (1995) op. cit.

80 Sujan, M. and Dekleva, C. (1987) 'Product categorisation and inference making: Some implications for comparative advertising', Journal of Consumer Research, Vol. 14, No. 3, pp. 372-378.

81 Hyndman (1990) op. cit.

82 Omisakin (1997) op. cit.

83 Paton (2002) op. cit.

84 Hyndman and McKillop (1999) op. cit.

85 Steinberg (1986) op. cit.

86 Margolis (2001) op. cit.

87 Baber et al. (2001) op. cit.

88 Paton (2002) op. cit.

87 Since 1995 British charities have effectively been obliged to adhere to a standard format when presenting information on their incomes and spending. In 1994 the UK Accounting Standards Body issued a Statement of Recommended Practice (SoRP) on the content and layout of charity accounts. The Charity Commission did not make the adoption of the SoRP mandatory for registered charities but, if a charity did not follow it and if this led to a 'distorted view', then the Commission would take action against its Trustees. The latter are legally obliged to 'ensure as accurate a picture as possible' (see Palmer and Vinten (1998) op. cit.). 
88 Saxon-Harrold et al. (1987) op. cit.

89 Fenton (1993) op. cit.

90 Bennett and Gabriel (2000) op. cit.

91 Mason et al. (2001) op. cit.

92 Differential elevation can be rewritten as $\left(\sigma\left[\bar{R}_{i}\right]-\sigma\left[\bar{A}_{i}\right]\right)^{2}$, ie the squared difference between the standard deviation of the average value of the ratings and the standard deviation of the average value of the true values. Likewise, $(D A)^{2}$ can be expressed as $\left(\sigma\left[R_{i j}\right]-\sigma\left[A_{i j}\right]\right)^{2}$.

93 Bennett and Gabriel (2001) op. cit.

94 Mason et al. (2001) op. cit., p. 315.

95 Mason and Bequette (1998) op. cit.

96 Saxon-Harrold et al. (1987) op. cit.

97 Warwick (1994) op. cit.

98 Sargeant et al. (2000) op. cit.

99 Mason et al. (2001) op. cit.

100 Sargeant et al. (2000) op. cit., p. 328. 